\title{
Noise in turbulence measurements using acoustic Doppler velocimetry
}

Babak Khorsandi

Department of Civil Engineering and Applied Mechanics, McGill University, Montreal, H3A 2K6, Canada

Laurent Mydlarski

Department of Mechanical Engineering, McGill University, Montreal, H3A 2K6,

Canada

Susan Gaskin

Department of Civil Engineering and Applied Mechanics, McGill University, Montreal, H3A 2K6, Canada

email: laurent.mydlarski@mcgill.ca

\section{ABSTRACT}

To validate the use of acoustic Doppler velocimeters (ADVs) for the measurement of turbulent flows, experiments were conducted in i) an axisymmetric turbulent jet, and ii) approximately homogenous isotropic turbulence with zero mean flow. The jet experiments show that the horizontal RMS velocities measured by the ADV were overestimated when compared to both flying hot-film anemometry measurements and 
the accepted values in the literature. However, the vertical component of the RMS velocity agrees well with those of other studies. This was furthermore confirmed by the ADV measurements in the isotropic turbulence with zero mean flow. Given that the overestimated RMS velocities in the horizontal directions may be due to Doppler noise and spikes, two post processing filters and the Doppler noise reduction method of Hurther and Lemmin (2001) were applied to the jet data, in an attempt to correct the data. Although, the RMS velocities decreased, they remained erroneously higher than the accepted values. We present a noise reduction method for axisymmetric flows that corrects the RMS velocities to within the range of acceptable values. Lastly, as the Doppler noise is thought to depend on the mean velocity (Lemmin and Lhermitte, 1999), a series of laboratory experiments were undertaken to relate Doppler noise to the mean velocity. The results showed no clear relationship between the Doppler noise and the mean flow. In addition, subtracting the Doppler noise (measured for a given mean velocity) from the measured RMS velocities (at the same mean velocity) did not significantly decrease the RMS velocities.

\section{INTRODUCTION AND LITERATURE REVIEW}

Acoustic Doppler velocimetry is used extensively as a research tool and frequently employed in hydraulic engineering applications, both in the field (oceans, lakes and rivers) and in the laboratory. Acoustic Doppler velocimeters (ADVs) have many advantages compared to other velocity measurement techniques, such as: robustness, the ability to measure in non-clean environments, the capability of three-dimensional instantaneous velocity measurements at moderately high sampling rates, the lack of a need for calibration, the separation of the measurement volume and the sensor (minimizing any interference with the flow), portability, and relatively low cost. These 
advantages make the ADV a popular velocity measurement instrument, particularly in field studies.

The ADV consists of a probe, connected, by either a fixed stem or a cable, to the housing, which contains the electronics. The sampling volume is located approximately $50 \mathrm{~mm}$ below the probe, which minimizes the interference of the probe with the flow. The probe consists of a transmitter and three or four receivers, which are equally angled and symmetrically arranged around the transmitter. The ADV relies on the Doppler effect to measure the velocity of particles suspended in the flow. Details of its operation can be found the work of Voulgaris and Trowbridge (1998) and McLelland and Nicholas (2000), as well as the Vectrino Velocimeter User Guide (2004).

As a relatively new instrument, the ADV needs to be validated in known flows to investigate its accuracy and sources of error. The ADV has been found to accurately predict the mean velocity and the Reynolds shear stresses in turbulent shear flows (Lohrmann et al., 1994; Voulgaris and Trowbridge, 1998; McLelland and Nicholas, 2000; Hurther and Lemmin, 2008). However its accuracy in measuring turbulence quantities such as the normal components of the Reynolds stresses, turbulent kinetic energy, and the turbulence microscales has been questioned (Nikora and Goring, 1998; Voulgaris and Trowbridge, 1998; Cea et al., 2007; Hurther and Lemmin, 2008). It can be assumed that the measured velocity in each bistatic axis consists of the true velocity and unbiased noise, $\left.\left.<u_{i}^{2}\right\rangle=<u_{T i}^{2}\right\rangle+\sigma_{i}^{2}$, and the noise is identical for each bistatic axis, $\sigma_{i}=\sigma$. Using this assumption, Voulgaris and Trowbridge (1998) showed that the quality of the variance $\left(<u_{i}^{2}>\right.$ or $\left.u_{r m s}{ }^{2}\right)$ and the covariance $\left(<u_{i} u_{j}>\right)$ of the measured orthogonal velocities depends on the noise variance along each bistatic axis $\left(\sigma^{2}\right)$ and the 
transformation matrix that is used to convert the velocities measured along bistatic axes to orthogonal components. Based on the transformation, they showed that the noise contribution is $O\left(10^{-2}\right) \times<\sigma^{2}>$ to the covariance, $O\left(10^{-1}\right) \times<\sigma^{2}>$ to the variance of the vertical velocity and $O\left(10^{1}\right) \times<\sigma^{2}>$ to the variance of the horizontal velocities for a SONTEK ADV. (See Figure 1 for the orientation of horizontal and vertical velocities.) Therefore, the effect of noise is more significant on the horizontal RMS velocities than on the vertical RMS velocity and the Reynolds shear stresses.

Voulgaris and Trowbridge (1998) divided the source of the noise into three categories:

(i) Sampling error related to the accuracy of the ADV's A/D board in resolving the changes in phase. This error is independent of the flow and depends on the pulse length, which is set by the velocity range of the ADV.

(ii) Doppler noise, which is an intrinsic feature of all Doppler backscatter systems and is flow-related. This noise is due to (1) turbulence and particle scattering, (2) beam divergence, and (3) the finite residence time of the particles in the sampling volume.

(iii) The error due to mean velocity gradients in the sampling volume. This error becomes important in flows with sharp-velocity-gradients, such as boundary layers.

The most significant source of noise in ADV turbulence measurements is Doppler noise, which is inherent to the technique (Garbini et al., 1982; Lohrmann et al., 1994). Doppler noise is a "white" noise, which does not influence the mean velocity. However it adds a positive bias to the high frequency range of the power spectrum, affecting the turbulence statistics (Dombroski and Crimaldi, 2007). Hurther and Lemmin (2001) 
characterized the Doppler noise as: i) having a flat spectrum over the frequency domain; ii) being unbiased $\left(<\sigma_{i}>=0\right)$, therefore not affecting the mean velocity; iii) being statistically independent of the true velocity fluctuations and true Doppler frequency; and iv) having statistically independent noise from one receiver to the next $\left(<\sigma_{i} \sigma_{j}\right\rangle=0$, $i \neq j$ ). (Furthermore, the relatively large sampling volume of the ADV can also limit its accuracy in turbulence measurements because smaller scales of a given flow may not be resolved by the ADV.) Doppler noise reduction methods have also been proposed with the aim of removing Doppler noise from the ADV's measured velocities. Nikora and Goring (1998) carried out velocity measurements with the ADV in a quiescent background and considered the signal measured therein as Doppler noise. Assuming the correlation between the velocity and the noise to be zero, they subtracted the measured noise from the measured velocity to estimate the true velocity. However, Lemmin and Lhermitte (1999) rejected this method remarking that the Doppler noise should be an increasing function of the flow's mean velocity and velocity measurements in the quiescent background therefore do not predict the Doppler noise. Hurther and Lemmin (2001) presented a correction method for subtracting the contribution of the noise from the mean turbulence parameters. In this method, the normal Reynolds stress term can be estimated from the covariance of two quasi-instantaneous vertical velocities measured simultaneously in the same sampling volume, assuming that the noise signal is random and statistically independent. Therefore, the variance of the noise can be calculated (from vertical velocities) and removed from the variance of the horizontal velocity components based on the geometrical configuration of the probe, assuming that the receiver transducers are identical and ideal and, therefore, that the noise level is the same along each bistatic axis $\left(<\sigma_{i}^{2}>=<\sigma^{2}>\right)$. 
Turbulence measurements are not only affected by Doppler noise, but also by random spikes. In contrast with Doppler noise, random spikes are not inherent to the measurement technique and occur mostly in poor measurement environments (Doroudian et al., 2010). To reduce the effect of noise resulting from random spikes, several post-processing filters have been proposed with the aim of improving the turbulence statistics measured by ADVs. These include the phase-space-thresholding method of Goring and Nikora (2002) and the despiking filters of Cea et al. (2007) and Parsheh et al. (2010). The latter reasoned that the phase-space-thresholding despiking method (Goring and Nikora, 2002; Wahl, 2003) erroneously removes some valid data points in the vicinity of the spikes (in addition to removing the spikes themselves). They modified the phase-space-thresholding despiking method so that the data points near the PDF peak were not affected by the despiking method, as these points are indeed "physical" and not spurious. Furthermore, the modified method replaces the spikes by the last valid data point instead of leaving a gap in the time series. It was shown that the modified method improved the spectrum over all frequencies compared to the original despiking method. Spike-removal, however, depends on the flow conditions and caution should be taken when proposing universal guidelines (Doroudian et al., 2010). Chanson et al. (2008) used an ADV for high-frequency velocity measurements in a small estuary. They showed that i) the ADV data measured in an unsteady estuary flow cannot be used without post-processing, and ii) conventional despiking methods such as the phase-space thresholding method (Goring and Nikora, 2002) were not sufficient. They proposed a post-processing procedure to improve their turbulence statistics. This procedure includes (i) a velocity signal check, where the low-signal-to-noise and lowcorrelation data are removed, (ii) pre-filtering or removal of large disturbances induced by aquatic life, navigation and experimental procedures, and (iii) despiking or removal 
of small disturbances. Their results showed that the mean velocity, as well as the statistics of the turbulence, were improved after their post-processing procedure. Doroudian et al. (2010) combined a despiking method with a noise-reduction method to improve turbulence measurements using an ADV. They applied the despiking method to the bistatic velocities before the orthogonal velocities were calculated. They used the spike removal method of Cea et al. (2007), in which the data points that exceeded three standard deviations from the mean were removed and replaced by the median of the time series - a procedure that was repeated twice. For the Doppler noise-reduction, the method of Hurther and Lemmin (2001) was applied to the data. The results showed that using both the despiking and the noise-reduction methods improved the overestimated RMS velocities. However, the effect of Doppler noise was shown to be significantly larger than the random spikes, e.g., in the seeded flow sampled at $25 \mathrm{~Hz}$, the RMS velocity was reduced by i) $5 \%$ after applying the despiking method, ii) $20 \%$ after applying the Doppler noise-reduction method, and iii) $24 \%$ after applying both methods.

There have also been studies that focused on the effect of the sampling frequency of the ADV on the turbulence statistics. McLelland and Nicholas (2000) estimated the contribution of noise to the velocity variance at various sampling frequencies at different mean velocities and depths in a channel flow. They showed that although higher sampling frequencies can characterize a larger range of turbulence frequencies, the total noise in the velocity variance increases at higher sampling rates. Garcia et al. (2005) showed that an ADV acts as a low-pass filter when acquiring data. To minimize this effect, they proposed a sampling strategy based on the flow conditions to ensure the resolution of turbulence statistics of all frequencies. It was shown in that if the ratio of 
the (user-set) sampling frequency of the ADV to the flow's characteristic sampling frequency was above 20, the loss of resolution of high-frequency turbulence fluctuations would be minimal. However, Doroudian et al. $(2007,2010)$ claimed that the observed decrease in velocity variance with decreasing sampling frequency could be mostly attributed to the noise instead of filtering effects due to the inherent low-pass filtering related to the ADV's sampling frequency. Lastly, based on the works of Garcia et al. (2005), Chanson et al. (2007), and Doroudian et al. (2007), Garcia et al. (2007) have developed general guidelines to perform velocity measurements using ADVs in turbulent flows.

Given that both Doppler noise and random spikes add a positive bias to the spectrum and thus overestimates the RMS velocities measured by the ADV, the ability of the ADV to measure turbulence statistics, and particularly RMS velocities (as well as the noise involved with such measurements), requires further investigation. Therefore, a rigorous validation of the performance of ADVs in a well established flow like turbulent jet can shed light on the noise problems associated with this technique

In this study, we attempt to validate the acoustic Doppler velocimeter, improve the (overestimated) RMS velocities and study the nature of the Doppler noise. The experimental setup and apparatus will be discussed first. The results will then be presented in three parts. In the first one, the turbulence statistics measured with the ADV in both a turbulent jet and an approximately homogenous isotropic turbulence with zero mean flow will be compared with those measured by flying hot-film anemometry in the same flows, as well as with those of the literature. It will be shown that i) the flying hot-film anemometry system developed in this work is an accurate 
reference as its results will be shown to be consistent with canonical measurements of the velocity field of a turbulent jet, and ii) the ADV predicts the mean velocity of the turbulent jet with reasonable accuracy; however it overestimates the RMS velocities measured along the horizontal components of the probe. In the second part of the Results section, we will attempt to improve the jet statistics measured with the ADV. We use existing post-processing filters and a noise reduction method suggested in the literature, then one new method proposed herein. In third part, we attempt to relate the Doppler noise to the mean velocity, and estimate its effect on the turbulence statistics. In this latter section, the measurements are made in i) a quiescent background, ii) a quiescent background with an artificially generated mean velocity by moving the ADV at a constant speed using a traversing mechanism, iii) homogeneous isotropic turbulence with no mean flow, and iv) homogeneous isotropic turbulence with an artificially generated mean velocity by moving the ADV at a constant speed using a traversing mechanism. Finally, conclusions are presented.

\section{EXPERIMENTS}

The experiments were conducted in a $1.5 \mathrm{~m}$ by $2.4 \mathrm{~m}$ by $0.9 \mathrm{~m}$ section of a $(1.5 \mathrm{~m}$ by $6 \mathrm{~m}$ by $1 \mathrm{~m}$ ) glass tank filled with water, open to the ambient air at the top, and located in the Environmental Hydraulics Laboratory of the Civil Engineering and Applied Mechanics Department at McGill University. A schematic of the apparatus is given in Figure 2. The tank consists of a steel frame, glass walls and a glass bottom. For the turbulent jet benchmarking experiments, a jet of circular cross section was mounted on a traversing mechanism. The $1.6 \mathrm{~m}$ high jet entered vertically into the water, then, $45 \mathrm{~cm}$ below the water's surface, extended horizontally for $0.12 \mathrm{~m}$ (after a $90^{\circ}$ bend). The flow upstream of the bend was fully-developed, and it was estimated to 
be close to or fully-developed at the jet exit (after the bend). Note that although the velocity profiles at the jet exit might have an effect on the initial development region $(\mathrm{x} / \mathrm{D} \leq 30)$, the statistics in the self-similar region are not affected by the initial conditions (Ferdman et al., 2000; Xu and Antonia, 2002) The turbulent jet was constructed of a copper tube, which was $8 \mathrm{~mm}$ in diameter. A constant head reservoir fed the jet with water and a flowmeter was used to set the flow rate. The exit velocity of the jet was $1.33 \mathrm{~m} / \mathrm{s}$, corresponding to a Reynolds number of 10,600 . The details of the jet and related apparatus can be found in Khorsandi (2011).

A random jet array (RJA) based on that of Variano et al. (2004) and Variano and Cowen (2008), but built to a larger scale was constructed to generate background turbulence. The RJA consists of an array of $6 \times 10$ bilge pumps (Rule $25 \mathrm{D}, 500 \mathrm{GPH}$ ) mounted on a $1 \mathrm{~m}$ by $1.5 \mathrm{~m}$ vertical sheet of high density polyethylene. The pumps take in water radially at their base and discharge it axially from an outlet perpendicular to the plane of the RJA. The spacing of the pumps was uniform in the horizontal and vertical directions (with a center to center distance of $0.15 \mathrm{~m}$ ). Reflectional symmetry at the walls was employed to lessen the possibility of secondary circulations, in analogy with oscillating grid turbulence (Fernando and De Silva, 1993; Variano et al., 2004; Variano and Cowen, 2008). Downstream of the RJA, the jets merge and create an approximately homogeneous isotropic turbulence with almost zero mean flow. The jet array is controlled by a LabVIEW program which independently and randomly turns the pumps on and off. The on and off times were determined from a normal distribution of variable mean and standard deviation (Variano and Cowen, 2008). Furthermore, a range of different average on times $\left(\mu_{o n}\right)$, average off times $\left(\mu_{o f f}\right)$ and standard deviations $(\sigma)$ was 
tested to come up with the optimum case in which $\left(\mu_{o n}, \sigma_{o n}\right)=(12,4) \mathrm{s}$, and $\left(\mu_{\text {off }}, \sigma_{\text {off }}\right)$ $=(108,36) \mathrm{s}$. In this algorithm, $10 \%$ of the pumps were on at a time, on average.

The velocity field was measured by a Nortek Vectrino 10-MHz acoustic Doppler velocimeter. The Vectrino ADV probe was mounted on a cable connected to its main housing. The probe consisted of a central transmitter (which sent the acoustic pulses) surrounded by four receivers that collected the signals reflected off the particles in the sampling volume. The accuracy of the velocity signal was $0.5 \%$ of the sampling range, selected to be $\pm 10, \pm 30$ or $\pm 100 \mathrm{~cm} / \mathrm{s}$ (depending on the position in the flow), which spanned the entire range of measured velocities. The sampling rate was $25 \mathrm{~Hz}$ (the maximum). A constant and maximum value was chosen to i) ensure that the Doppler noise was consistent in all experiments, and ii) minimize any filtering of higherfrequency components of the velocity fluctuations, consistent with Garcia et al. (2005), who suggest finding an optimum sampling frequency that balances the competing effects of minimizing any filtering of the data and minimizing the Doppler noise. 102400 data points were recorded (at $25 \mathrm{~Hz}$ ) for a total record length of 68 minutes. It was found that statistics up to fourth-order (i.e., kurtosis) were converged with data sets of this length, consistent with the results of Chanson et al. (2007). The sampling volume of the ADV was located approximately $5 \mathrm{~cm}$ below the probe and was set to its maximum of $0.26 \mathrm{~cm}^{3}$. The $5 \mathrm{~cm}$ distance between the probe and sampling volume minimizes the flow interference. The ADV operates by measuring acoustic signals reflected off particles in the flow. Therefore neutrally-buoyant, 9-13 $\mu \mathrm{m}$ diameter glass particles (Potters Industries Sphericel hollow glass spheres) were added to the filtered water to increase the signal-to-noise ratio (SNR) of the ADV. The power level was also set to the highest setting to have maximum SNR. The ADV was connected to a 
computer system from which the ADV parameters were set and the data were acquired through the manufacturer's software.

Before each test, the velocity range was set to span the entire range of measured velocities. The SNR and correlation parameters were checked before each experiment to ensure they met the minimum acceptable values specified by the ADV manufacturer: 15 $\mathrm{dB}$ and $70 \%$, respectively. If enough glass particles were mixed in the water, the SNR and the correlation was high. In the near-field $(\mathrm{x} / \mathrm{D}<30)$ jet measurements, the SNR and the correlation were smaller because the jet water did not contain particles. However, as the jet mixed and entrained ambient fluid (and therefore particles) farther downstream, the SNR and the correlation increased to higher than $20 \mathrm{~dB}$ and $70 \%$, respectively. Therefore, jet measurements were only conducted at $x / D>30$. In the background turbulence generated by the RJA, the SNR was greater than $20 \mathrm{~dB}$ and the correlation was always 99\%. In addition, the SNR and the correlation decreased significantly in the vicinity of the tank walls. Therefore, measurements close to the walls were not taken - the sampling volume was never closer than $45 \mathrm{~cm}$ above the bottom wall of the tank, which is sufficient to avoid any spikes from acoustic reflections off the tank bottom (Chanson et al., 2007). Lastly, PDFs of our (untreated) data (not shown) were found to be are unimodal, Gaussian, and without excessively long tails, similar to the reconstructed and spike-free PDFs of Parsheh et al. (2010), indicating that spikes in the time series of velocity were not a significant source of error. This is attributed to the high signal quality in our laboratory measurement.

Measurements in the same flows using a flying hot-film anemometer were carried out to compare with those of the ADV. The flying hot-film anemometry setup consisted of a TSI 1210-20W hot-film sensor and a DISA 55M10 anemometer. A Krohn-Hite 
filter (Model 3382) was used for low-pass filtering of the background turbulence data (at $500 \mathrm{~Hz}$, and sampled at $1000 \mathrm{~Hz}$ ). A high-precision linear traversing mechanism was positioned above the tank and parallel to the RJA to move the flying hot-film (or the ADV in the final part of the Results section) at a constant speed. This traversing mechanism was also used to calibrate the hot-film. The traversing mechanism consisted of an Aerotech BLMUC-143-A linear DC motor and a Schneeberger Monorail AMSD4A. Both were connected to an Aerotech SOLOIST CP10 controller. A $\pm 10 \mathrm{~V}$, 16-bit data acquisition system was developed and used to simultaneously acquire the flying hot-film anemometer output voltage. The anemometer output voltage and position (taken from an encoder mounted on the traversing mechanism) were recorded using an FPGA (field-programmable gate array) card and a customized LabVIEW program. (See Khorsandi 2011 for details.) In this program, the data was acquired only when the hot-film probe was moving in the direction in which the sensor was pointing. For the jet experiments, this direction and (thus the data acquisition) was from downstream to upstream positions in the jet. There was also a waiting time between passes to allow the flow disturbance caused by the movement of the hot-film probe to dissipate.

In contrast to the ADV measurements, the hot-film anemometry measurements required clean water to reduce probe fouling. (Furthermore, it also necessitated a controlled, constant water temperature.) A Jacuzzi Laser sand filter in series with a Hayward EC65A filter was used to clean the water upon entering the tank. Once the tank was full, the latter filter was used to continuously filter particles of size greater than $2 \mu \mathrm{m}$ from the water in a recirculation loop, using a $1 \mathrm{hp}$ pump to circulate the water into and out of the unused portion of the tank, so as not to induce any flow in the section in which the experiments were performed. The water was pumped from outlets 
of the tank through the filter and then back to the inlets of the tank. Algaecide was also added to the water. The combination of filtration and algae inhibitor minimized the (hot-film) probe fouling during flying hot-film experiments.

\section{RESULTS}

In the first of the 3 parts of this section, the validation of the flying hot-film anemometer and ADV are discussed. It will be shown that i) the flying hot-film anemometer is accurate and its data is consistent with previous measurements of a turbulent jet, and ii) the ADV overestimates the RMS velocities. In the second and third sections, we attempt to correct the ADV results i) using existing and new postprocessing methods; and ii) by relating the mean velocity to the Doppler noise, and subsequently, subtracting the noise at a given mean velocity from the overestimated RMS velocities.

\section{VALIDATION}

\section{Measurements in an axisymmetric turbulent jet}

Being a thoroughly studied turbulent flow, the turbulent jet was selected to validate the ADV's and flying hot-film anemometer's performance. The mean velocities, spreading rate and RMS velocities measured with the ADV will be presented in this section. The results will be compared to those of stationary hot-film anemometry (SHFA) and flying hot-film anemometry (FHFA), as well as the results of previous studies - the stationary hot-wire anemometry (SHWA) measurements of Wygnanski and Fiedler (1969), the flying hot-wire anemometry (FHWA) measurements of Panchapakesan and Lumley (1993) and the SHWA, FHWA and laser Doppler anemometry (LDA) measurements of Hussein, Capp and George (1994). Furthermore, 
the comparison of the FHFA results with those of the three above-mentioned canonical works will confirm the accuracy of the FHFA measurements (and, consequently, the overestimates of the RMS velocities measured by the horizontal components of the ADV).

Figure 3 depicts the orientation of the jet relative to the ADV. (Note that the coordinate system therein differs from that shown in Figure 2, which pertains to the measurements made in the flow generated by the random jet array.) Figure 4 plots the downstream variation of the inverse of the mean axial velocity $\left(U_{J} /<U_{C L^{>}}\right.$, where $U_{J}$ is the nozzle exit velocity) along the jet's centerline. $x$ is the downstream distance from the jet exit and $D$ is the diameter of the jet nozzle. The jet Reynolds number, $R e=U_{J} D / v$, is 10,600 . In this graph, the ADV data is compared with the present stationary and flying hot-film data, as well as the results of Wygnanski and Fiedler (1969), Panchapakesan and Lumley (1993) and Hussein, Capp and George (1994). As can be seen, the mean velocity along the centerline measured with the ADV agrees well with that of the stationary hot-film, flying hot-film and those of the other studies. (Note that the flying hot-film data diverges from the previous research far downstream, where the jet velocities become especially small.)

The mean axial velocity of a jet emitted into a quiescent background is known to decay as $x^{-1}$ in the self-similar region, such that: $<U_{C L}(x)>/ U_{J}=B /\left[\left(x-x_{0}\right) / D\right]$, where and $D$ is the diameter of the jet nozzle, $x_{0}$ is the virtual origin and $B$ is a constant. The decay constant $(B)$ is compared to those of previous experiments in Table 1. As can be seen, the decay constant agrees well with those of the other studies, especially that of Panchapakesan and Lumley (1993), which is at a very similar Reynolds number. This 
further validates the accuracy of acoustic Doppler velocimetry and the FHFA for mean flow measurement.

The normalized mean velocity profile $\left(<U(r)>/<U_{C L}>\right)$ plotted as a function of the normalized jet width $(r / x)$ results in a universal profile of the jet, which is not a function of downstream distance (nor Reynolds number) in the self-similar region of the jet. The radial profile of $\left\langle U(r)>/<U_{C L}>\right.$ measured at $x / D=35$ is presented in Figure 5. The mean velocity profile measured with the ADV is in relatively good agreement with that of the flying hot-film anemometer, as well as the data of Wygnanski and Fiedler (1969) (measured at $\mathrm{x} / \mathrm{D}=50$ ), Panchapakesan and Lumley (1993), and Hussein, Capp and George (1994) (measurement locations were not mentioned for these studies) although it exhibits a tendency towards slightly smaller values. The flying hot-film anemometer data are in excellent agreement with those of previous researchers.

The half-width $\left(r_{1 / 2}\right)$ of the jet is defined as the radial position at which the velocity falls to half of its value at the centerline (for a given downstream distance). The halfwidth of the jet in a quiescent background grows linearly with the downstream distance in the self-similar region: $r_{1 / 2}=S\left(x-x_{0}\right)$, where $S$ is defined as the jet spreading rate (Pope, 2000). The spreading rate $(S)$ is compared to the previous experiments listed in Table 1. It can be seen that this quantity agrees well with those of the other studies, for both the FHFA and the ADV. Pope (2000) also notes that the spreading rate is independent of the Reynolds number.

Figure 6 plots the axial RMS velocity normalized by the mean velocity $\left(u_{r m s} /<U_{C L}>\right)$ at the jet centerline. Similar to the mean velocity, the RMS velocity 
decays as $x^{-1}$. Therefore, RMS velocities normalized by mean velocities at the centerline asymptote to a constant in the self-similar region. Although some variations in this quantity have been observed in the literature, no systematic dependence on the Reynolds number has been found (Pope 2000). Wygnanski and Fiedler (1969), and Hussein, Capp and George (1994) measured $u_{r m s} /<U_{C L}>$ to be approximately 0.28 in the self-similar region, whereas Panchapakesan and Lumley (1993) measured a value of 0.24. In the present study, $u_{r m s} /<U_{C L}>$ at the centerline of the jet in the self-similar region is found about 0.27 when measured using both stationary and flying hot-film anemometry, consistent with the previous experiments, while $u_{r m s} /<U_{C L}>$ measured by the $\mathrm{ADV}$ is about 0.35 . The ADV significantly overestimates $u_{r m s} /<U_{C L}>$ when compared to the flying hot-film anemometer data as well as those of other studies. As the mean velocity along the centerline is predicted relatively accurately by the ADV, the overestimation must be due to abnormally large RMS velocities. In addition, the RMS velocities measured with the ADV reach self-similarity farther downstream when compared to the flying hot-film and have higher variations in the range of $30 \leq \mathrm{x} / \mathrm{D} \leq$ 110 when compared to those of the flying hot-film anemometry and Panchapakesan and Lumley (1993) results.

Lateral RMS velocities normalized by the mean velocity $\left(v_{r m s} /<U_{C L}>\right.$ and $w_{r m s} /<U_{C L}>$ ) measured by $\mathrm{ADV}$ at the jet centerline are shown in Figure 7. By symmetry, $v_{r m s}$ and $w_{r m s}$ should be the same at the centerline of an axisymmetric jet, however the ADV measurements result in $v_{r m s} /<U_{C L}>$ of about 0.30 , and $w_{r m s} /<U_{C L}>$ of about 0.19 , in the self-similar region. The lateral RMS velocity normalized by the mean velocity at the centerline is estimated to be $0.25,0.19$ and 0.21 by Wygnanski and Fiedler (1969), Panchapakesan and Lumley (1993) and Hussein, Capp and George 
(1994), respectively. Therefore, only $w_{r m s} /<U_{C L}>$ agrees well with the results of other studies when measured by the ADV.

The comparison of the RMS velocities measured by the ADV with those of the flying hot-film, Wygnanski and Fiedler (1969), Panchapakesan and Lumley (1993) and Hussein, Capp and George (1994) shows that the ADV overestimates $u_{r m s}$ and $v_{r m s}$, which are measured along the $x$ - and $y$-directions of the probe. On the other hand, $w_{r m s}$ measurements (along the $z$-direction of the probe) are found to be relatively accurate. As previously discussed, the high error in $u_{r m s}$ and $v_{r m s}$ can be explained by the geometrical configuration of the ADV probe, which has higher noise in the $x$ - and $y$ directions compared to the $z$-direction (Voulgaris and Trowbridge, 1998). To improve our $u_{r m s}$ and $v_{r m s}$ measurements, we will apply noise reduction filters, as proposed in the literature, in next part of the present Results section.

Figure 8 plots velocity spectra of all three velocity components measured at the jet centerline using the $\mathrm{ADV}$, at $\mathrm{x} / \mathrm{D}=50$ and 110 . As we can see, the $\mathrm{u}$ and $\mathrm{v}$ spectra have a higher noise floor. In addition, the $\mathrm{v}$ and the $\mathrm{w}$ spectra should collapse due to the axisymmetry of the jet. However, the v spectrum has artificially more turbulent kinetic energy because of noise. This confirms that the noise affects the spectrum at all frequencies, not just the highest ones.

\section{Measurements in a turbulent background}

To further benchmark the ADV, measurements were also conducted in an approximately homogeneous, isotropic, zero-mean-flow turbulence generated by an RJA (Figure 2). In contrast to the jet, this flow has nominally no mean flow $\left(<U>/ u_{r m s}<\right.$ $10 \%)$. Furthermore, note the change of coordinate systems used in this flow: $\mathrm{x}$ is in the 
downstream direction of the RJA (in the direction of the jets of the RJA) and $y$ and $z$ are in the transverse plane. The results measured at $\mathrm{x}=110 \mathrm{~cm}$ are presented in Table 2 . Flying hot-film anemometry was used to measure $v_{r m s}$. Measurements at the same location, but using two different orientations of the ADV probe were also conducted. In orientation 1 , the $u_{r m s}$ and $v_{r m s}$ velocities are aligned with the horizontal axes of the ADV probe ( $\mathrm{x}$ and $\mathrm{y}$ ) while the $w_{r m s}$ velocity is aligned with the vertical axis $(\mathrm{z})$. In orientation $2, u_{r m s}$ is along the vertical axis $(\mathrm{z})$ while $v_{r m s}$ and $w_{r m s}$ are along the horizontal axes of the ADV probe (negative $\mathrm{x}$ and negative $\mathrm{y}$ ). The turbulence generated by the RJA decays downstream and is homogenous in the transverse plane. Therefore, the statistics in the traverse plane, namely $v_{r m s}$ and $w_{r m s}$, are nominally the same. However, $v_{r m s}$ is about $20 \%$ higher than $w_{r m s}$ in orientation $1 . w_{r m s}$, which is measured along the z-axis of the ADV, agrees well with the RMS velocity measured by flying hot-film anemometry. This again validates the accurate measurement of the RMS velocities along the z-axis of the ADV. $v_{r m s}$ and $w_{r m s}$ (measured along negative $\mathrm{x}-$ and $\mathrm{y}-$ axis of the ADV probe, respectively) are the same in orientation 2, but overestimated when compared with both i) the RMS velocity measured by the flying hot-film anemometer in the transverse plane and ii) that measured by the vertical component of the ADV in orientation 1 . This is consistent with our jet measurements and confirms that the RMS velocities measured by the ADV are over-predicted in the $\mathrm{x}$ - and $\mathrm{y}$ directions of the probe, while the error in the w-component of the probe velocity is significantly smaller (and not dependent on the presence or lack of the mean velocity). The velocity spectra of the flow generated by the RJA (for both ADV orientations) are shown in Figure 9. We can see that the spectra measured along the horizontal axes of the ADV probe have artificially more turbulent kinetic energy because of noise. 
In this subsection, post-processing and noise reduction methods presented in the literature for flows measured by ADV will be applied and tested on the previouslydiscussed turbulent jet flow. We will also propose a noise reduction method for improving the RMS velocities measured along the axis of the jet.

The de-spiking filters of Goring and Nikora (2002) (the phase-space thresholding method modified by Wahl (2003), which is used in the SONTEK data analysis software, WinADV) and Cea et al. (2007) were tested on the current jet data. They, however, did not reduce the RMS velocities significantly as the signal quality was high in the present laboratory flow. They were therefore not beneficial in correcting the overestimated RMS velocity measurements discussed in the previous chapter.

We subsequently applied the noise reduction method of Hurther and Lemmin (2001). In general, other noise reduction filters detect spikes (which usually result from a low quality signal) and eliminate them, or remove data with low signal-to-noise ratio and/or correlation. However, Hurther and Lemmin (2001) deal with the noise problem more fundamentally. In their method, the Doppler noise is estimated from the two quasi-instantaneous vertical velocities (measured simultaneously in the same sampling volume) and then subtracted from the other velocity components. The Nortek Vectrino ADV used in this research measures two quasi-simultaneous vertical velocities along the z-direction of the probe. To find the Doppler noise, the covariance of the two vertical velocities $\left(<w_{1} w_{2}>\right)$ was first calculated. As the noise signals of the two vertical velocities can be reasonably assumed to be uncorrelated, the covariance is noise-free (Hurther and Lemmin, 2001). Therefore, the covariance is the same as the true variance 
(i.e., $<w_{1} w_{2}>=<w_{T 1}^{2}>=<w_{T 2}{ }^{2}>$ ). Assuming the correlation between the velocity and the noise to be zero, the covariance was subtracted from the measured variance (which includes the effects of Doppler noise) to find the variance of the noise for the wcomponent of the velocity $\left(<\sigma_{w}{ }^{2}>=<w_{\text {Measured }}{ }^{2}>-<w_{1} w_{2}>\right)$. If the receiver transducers are identical and ideal, we can assume that the noise variance is the same along each bistatic axis. Using the transformation matrix, the variances of the noise were then calculated for the $\mathrm{u}$ and $\mathrm{v}$ velocity components. Subsequently, the variance of the noise was subtracted from the variances of the $\mathrm{u}$ and $\mathrm{v}$ velocities to find the true variances (and therefore RMS velocities). The results are presented and compared with the uncorrected RMS velocities in Figure 10 and Figure 11. It can be seen that the noise reduction method improves the data. $u_{r m s}$ and $v_{r m s}$ decreased by up to $15 \%$ at some points, while $w_{r m s}$ did not change significantly, as expected. Although the RMS velocities measured by the ADV were improved using the noise reduction method of Hurther and Lemmin (2001), they nevertheless remained larger than those measured by the present flying hot-film anemometer measurements and previous studies.

In another attempt to improve the measurements of the jet RMS velocities, we estimated the noise in $v_{r m s}$ by subtracting the velocity spectrum of $\mathrm{w}$ (assumed to have negligible noise) from the velocity spectrum of $\mathrm{v}$, which results in the velocity noise spectrum for $v_{r m s}-$ see Figure 12. (The noise variance in the y-direction can also be found by subtracting the velocity variance in z-direction from that in y-direction, i.e., $<\sigma_{v}^{2}>=<v^{2}>-<w^{2}>$.) The variance of the noise in y-direction was then converted to that of the $\mathrm{x}$-direction using the transformation matrix (assuming that the noise is the same along each bistatic axis). The noise was then subtracted from $u_{r m s}$. The results, presented in Figure 10, show that $u_{r m s} /<U>$ calculated by this method, agrees well with 
the stationary hot-film data, flying-hot-film data and those of the other studies in the self-similar region. This method can be used to find the true RMS velocities: i) in axisymmetric flows, and ii) in any flow, if two measurements of the velocity spectra (or velocity variances) are made with the ADV oriented in two different directions.

\section{RELATIONSHIP BETWEEN DOPPLER NOISE AND MEAN VELOCITY}

A further series of experiments was conducted using the ADV in quiescent and turbulent backgrounds to investigate the relation between the Doppler noise and the mean velocity. For both background conditions, the ADV was either kept stationary or moved at a constant speed by the high-precision traversing mechanism which was used to move the hot-film probe for the flying hot-film experiments. The traversing mechanism speeds were $10 \mathrm{~cm} / \mathrm{s}$ and $20 \mathrm{~cm} / \mathrm{s}$ - values similar to the jet centerline velocities measured in the first set of experiments (at $x / D=75$ and $x / D=42.5$, respectively).

The results of these experiments are summarized in Table 3. As the pulse length (which is determined by the ADV's velocity range) contributes to the noise (Voulgaris and Trowbridge, 1998), the same velocity range $( \pm 0.3 \mathrm{~m} / \mathrm{s})$ was chosen for all the tests in this set of experiments. The velocity measured by the ADV in the quiescent background is presented in the first three columns of this table. In the first column, the velocity measured by the stationary ADV is shown. The second and third columns present the velocity statistics corresponding to the experiments in which the ADV was translated at constant speeds of $10 \mathrm{~cm} / \mathrm{s}$ and $20 \mathrm{~cm} / \mathrm{s}$, respectively, in the y-direction. The RMS velocities in a quiescent background should ideally be zero; therefore the measured RMS velocities are attributable to the different sources of experimental error. 
The RMS velocities shown in the first three columns are relatively small. Relative to the mean velocity, the RMS velocities are less than 3\% for the cases in which the ADV was moved at a constant speed. The results in this table also indicate no clear dependence of the noise on the mean velocity. Although the RMS velocities increased when the ADV traversing velocity increased from $10 \mathrm{~cm} / \mathrm{s}$ to $20 \mathrm{~cm} / \mathrm{s}$, the RMS velocities were lower when the ADV was translated at $10 \mathrm{~cm} / \mathrm{s}$ than for the stationary ADV. This may be due to increased noise from a weaker signal because the glass beads may be driven out of the measurement volume by acoustic streaming (Snyder and Castro, 1999; Poindexter et $a l ., 2011$ ) when there is no flow (and not replaced with beads from elsewhere in the flow).

Similar experiments were carried out in a turbulent background generated by the random jet array to investigate the effect of mean flow on the noise in the presence of background turbulence. The results are presented in the last three columns of the table. Similar to the measurements in the quiescent background, no clear relation can be observed between the RMS velocities and the mean velocity of the flow. In other words, the measured RMS velocities in a turbulent flow with no-mean velocity do not significantly differ from those measured in the same flow when imposing a constant mean velocity by translating the ADV. Hence, the Doppler noise does not appear to be a monotonic function of mean velocity, for the range of velocities studied herein, in contrast with the argument of Lemmin and Lhermitte (1999).

Finally, subtracting the velocity variances measured with the ADV moving at a constant speed in quiescent background from the measured jet and background turbulence velocity variance (assuming zero correlation between the velocity and noise 
signals), reduced the RMS velocities by less than $1 \%$. This is significantly less than our observed error in the ADV measurements made on the axis of a turbulent jet or in a turbulent background. This suggests that either the Doppler noise is a function of other parameters (which were not accounted for here), or there are other intrinsic sources of error in acoustic Doppler velocimetry.

\section{CONCLUSIONS}

In conclusion, for the flows considered herein, the ADV is a relatively accurate instrument for mean velocity measurements. The RMS velocities measured along the $\mathrm{x}-$ and $\mathrm{y}$-directions of the probe (or $\mathrm{u}$ and $\mathrm{v}$ horizontal velocity components) are significantly overestimated due to excessive Doppler noise while the vertical RMS velocity, which is measured in the z-direction of the probe, agrees well with other studies (because spurious spikes were not present in our controlled laboratory flow, in addition to this component having a relatively small level of Doppler noise). Among the noise reduction methods suggested in the literature, that of Hurther and Lemmin (2001) improved the turbulence statistics, however the corrected RMS velocities measured by the ADV were still higher than those measured by well established turbulence measurement techniques. We also presented a method for improving the turbulence statistics. This method improved the data and can be used in axisymmetric flows or if measurements with the probe in two different orientations are conducted. Nevertheless, further work remains to be done to improve the accuracy of the turbulence statistics measured with ADV. In addition, the turbulence statistics measured with the ADV should not be used without post-processing to remove spikes (if present) and Doppler noise. Although, the vertical velocity measured by the ADV is relatively accurate when

spikes are absent, theoretically permitting the z-direction of the probe to be used to 
measure correct turbulence statistics, orienting the probe so that the z-direction of the probe is aligned against the direction of the flow, e.g. along the jet axis, may result in a significant flow disturbance. Finally, no clear relationship was detected between the Doppler noise and the mean flow, in contrast with the argument of Lemmin and Lhermitte (1999). 


\section{REFERENCES}

Cea, L., Puertas, J., and Pena, L. 2007. Velocity measurements on highly turbulent free surface flow using ADV. Experiments in Fluids 42:333-348.

Chanson, H., Trevethan, M., and Koch, C. 2007. Discussion of "Turbulence Measurements with Acoustic Doppler Velocimeters" by Carlos M. García, Mariano I. Cantero, Yarko Niño, and Marcelo H. García. Journal of Hydraulic Engineering $133: 1283-1286$.

Chanson, H., Trevethan, M. and Aoki, S. 2008. Acoustic Doppler velocimetry (ADV) in small estuary: Field experience and signal post-processing. Flow Measurement and Instrumentation 19: 307-313.

Dombroski, D.E. and Crimaldi, J.P. 2007. The accuracy of acoustic Doppler velocimetry (ADV) measurements in turbulent boundary layer flows over a smooth bed. Limnology and Oceanography Methods 5:23-33.

Doroudian, B., Bagherimiyab, F. and Lemmin, U. 2010. Improving the accuracy of four-receiver acoustic Doppler velocimeter (ADV) measurements in turbulent boundary layer flows. Limnology and Oceanography Methods 8:575-591.

Doroudian, B., Hurther, D. and Lemmin, U. 2007. Discussion of "turbulence measurements with acoustic Doppler Velocimeters" by Carlos M. Garcia, Mariano I. 
Cantero, Yarki Nino, and Marcelo H. Garcia. Journal of Hydraulic Engineering 133: 1286-1289.

Ferdman, E., Ötügen, M.V. and Kim, S. 2000. Effect of initial velocity profile on the development of round jets. Journal of Propulsion Power, 16, 676-686.

Fernando, H.J.S. and De Silva, I.P.D. 1993. Note on secondary flows in oscillating-grid, mixing-box experiments. Physics of Fluids, A5 (7): 1849-1851.

Garbini, J.L., Forster, F.K. and Jorgensen, J.E. 1982. Measurement of fluid turbulence based on pulsed ultrasound techniques. Part 1. Analysis. Journal of Fluid Mechanics 118: 445-470.

Garcia, C.M., Mariano, I.C., Nino, Y. and Garcia, M.H. 2005. Turbulence measurements with acoustic Doppler velocimeters. Journal of Hydraulic Engineering 131: 1062-1073.

Garcia, C.M., Mariano, I.C., Nino, Y. and Garcia, M.H. 2007. Closure to "Turbulence Measurements with Acoustic Doppler Velocimeters" by Carlos M. García, Mariano I. Cantero, Yarko Niño, and Marcelo H. García. Journal of Hydraulic Engineering 133:1289-1292.

Goring, D.G. and Nikora, V.I., 2002. Despiking acoustic Doppler velocimeter data. Journal of Hydraulic Engineering 128(1): 117-126 
Hurther, D. and Lemmin, U., 2001. A correction method for turbulence measurements with a 3D acoustic Doppler velocity profiler. Journal of Atmospheric and Oceanic Technology 18, 446-458.

Hurther, D. and Lemmin, U., 2008. Improved turbulence profiling with field-adapted acoustic Doppler velocimeters using a bifrequency Doppler noise suppression method. Journal of Atmospheric and Oceanic Technology, 25(3), 452-463.

Hussein, H.J., Capp, S.P. and George, W.K. 1994. Velocity-measurements in a highReynolds-number, momentum-conserving, axisymmetrical, turbulent jet. Journal of Fluid Mechanics 258: 31-75.

Khorsandi, B. 2011 Effect of background turbulence on an axisymmetric turbulent jet. PhD dissertation, McGill University.

Lemmin, U. and Lhermitte, R. 1999. Discussion of 'ADV measurements of turbulence: Can we improve their interpretation? by V. I. Nikora, and D. G. Goring. Journal of Hydraulic Engineering 125_9: 987-988.

Lohrmann, A., Cabrera, R., and Kraus, N.C. 1994. Acoustic Doppler velocimeter (ADV) for laboratory use. In Proc. Symp. On Fundamentals and Advancements in Hydr. Measurements and Experimentation, C. A. Pugh, ed., ASCE, 351-365.

McLelland, S.J. and Nicholas, A.P. 2000. A new method for evaluating errors in a highfrequency ADV measurements. Hydrological Processes. 14:351-366. 
Nikora, V.I. and Goring, D.G. 1998. ADV measurements of turbulence: Can we improve their interpretation? Journal of Hydraulic Engineering 124(6): 630-634.

Panchapakesan, N.R. and Lumley, J.L. 1993. Turbulence measurements in axisymmetric jets of air and helium. Part 1. Air jet. Journal of Fluid Mechanics 246: 197-223.

Parsheh, M., Sotiropoulos, F. and Porte-Agel, F. 2010. Estimation of power spectra of acoustic-Doppler velocimetry data contaminated with intermittent spikes. Journal of Hydraulic Engineering 6: 368-378.

Poindexter, C.M., Rusello, P.J. and Variano E.A. 2011. Acoustic Doppler velocimeterinduced acoustic streaming and its implications for measurement. Experiments in Fluids 50: 1429-1442.

Snyder W.H. and Castro, I.P. 1999. Acoustic Doppler velocimeter evaluation in stratified towing tank. Journal of Hydraulic Engineering 125: 595-603.

Variano, E.A., Bodenschatz, E. \& Cowen, E.A. 2004. A random synthetic jet array driven turbulence tank. Experiments in Fluids 37: 613-615.

Variano, E.A. \& Cowen, E.A. 2008. A random-jet-stirred turbulence tank. Journal of Fluid Mechanics 604: 1-32. 
Vectrino Velocimeter User Guide, Nortek, 2004.

Voulgaris, G. and Trowbridge, J.H. 1998. Evaluation of the acoustic Doppler velocimeter $(\mathrm{ADV})$ for turbulence measurements. Journal of Atmospheric and Oceanic Technology 15: 272-289.

Wahl, T.L. 2003. Discussion of "Despiking Acoustic Doppler Velocimeter Data" by Derek G. Goring and Vladimir I. Nikora. Journal of Hydraulic Engineering 129:484488.

Wygnanski, I. and Fiedler, H. 1969. Some measurements in the self-preserving jet. Journal of Fluid Mechanics 38: 577-612.

Xu, G. and Antonia, R.A. 2002. Effect of different initial conditions on a turbulent round free jet. Experiments in Fluids 33: 677-683. 

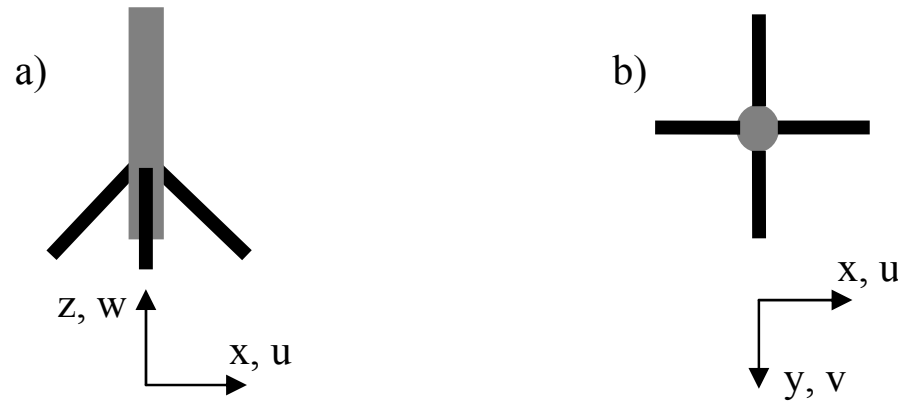

Figure 1. A Nortek Vectrino ADV probe with four receivers: a) side view, b) end/bottom view. Note that the velocity components in the $\mathrm{x}$ - and $\mathrm{y}$ - directions are referred to as horizontal velocities and the velocity component in the z-direction is referred to as the vertical velocity. 


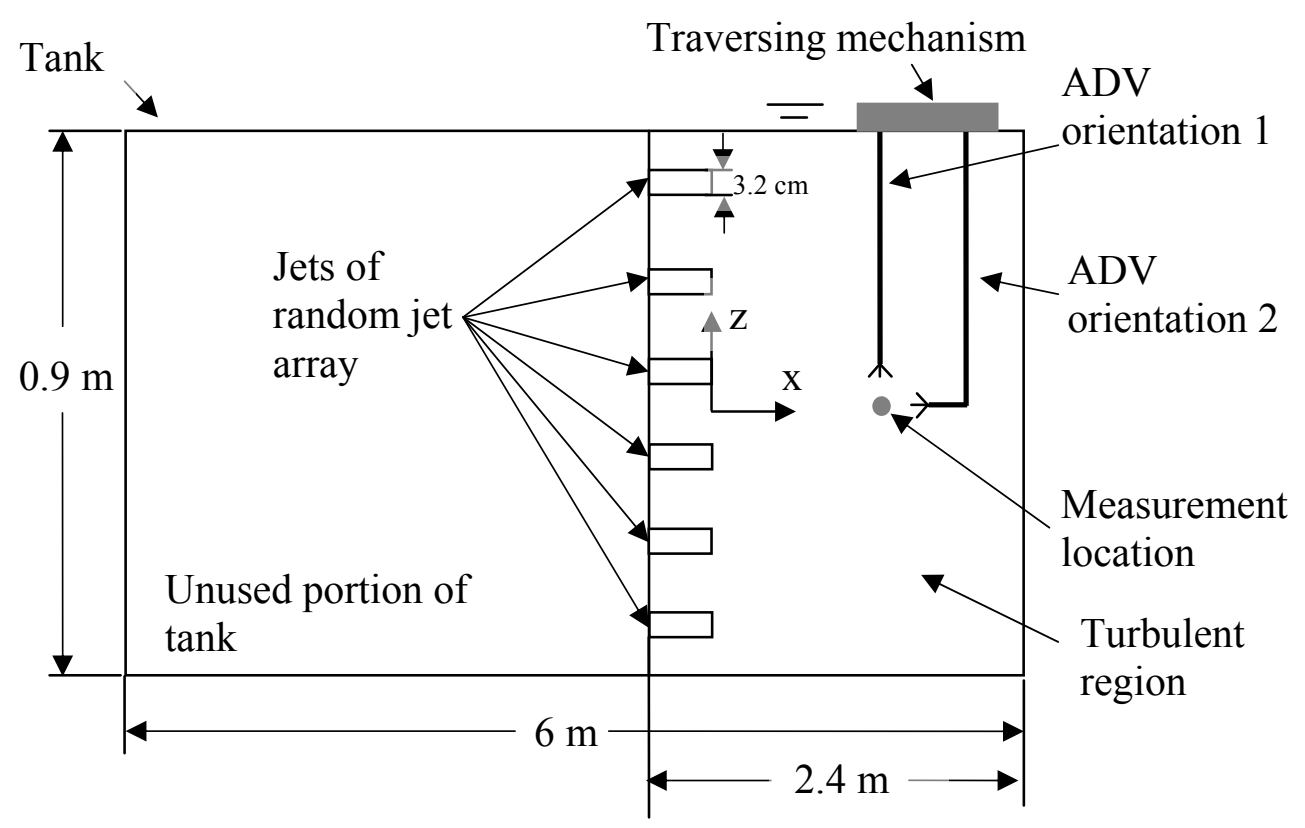

a) Side view

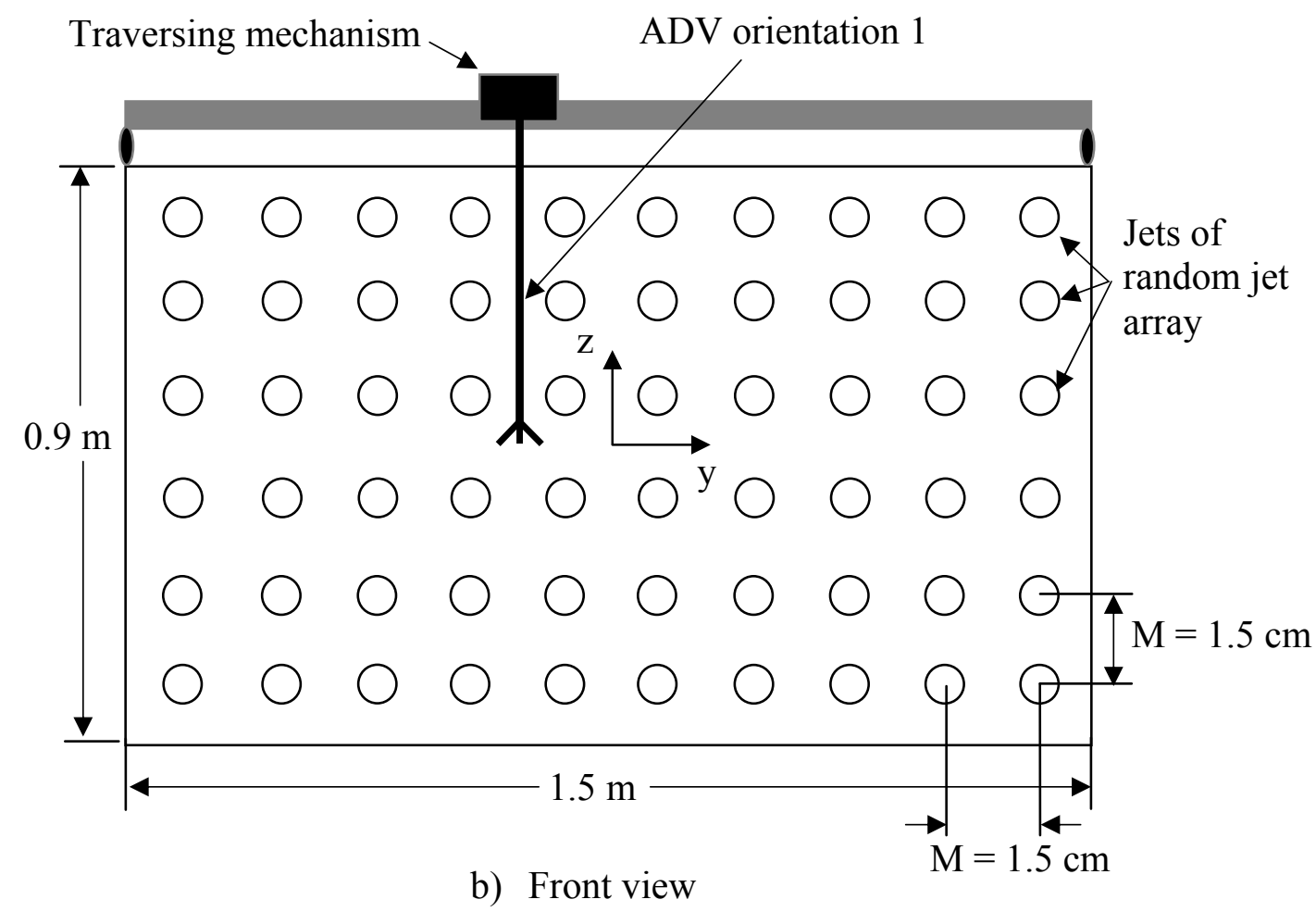

Figure 2. Schematic of the ADV, the RJA and the tank. (a) side view, (b) front view. (Not to scale.) Note that ADV orientation 2 is not shown in Figure 2(b) for the sake of clarity. 

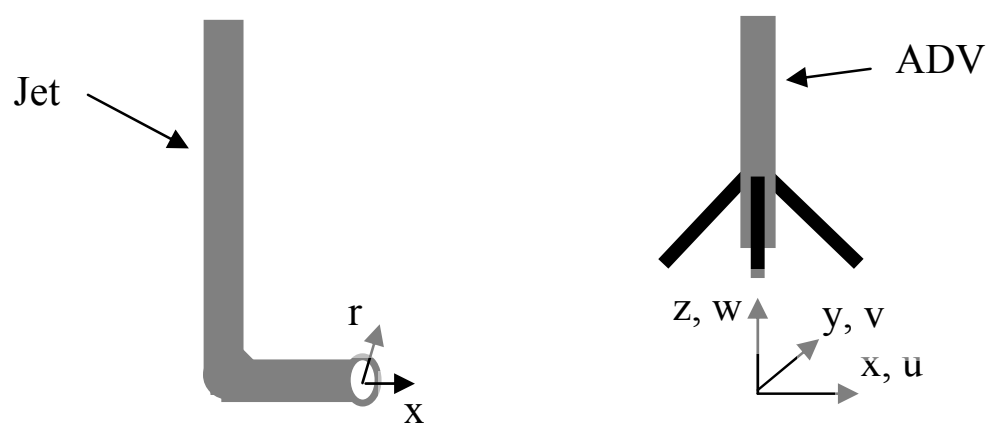

Figure 3. Schematic of the jet and the ADV probe. Note that this coordinate system is different than that used when measuring in the flow generated by the random jet array. 


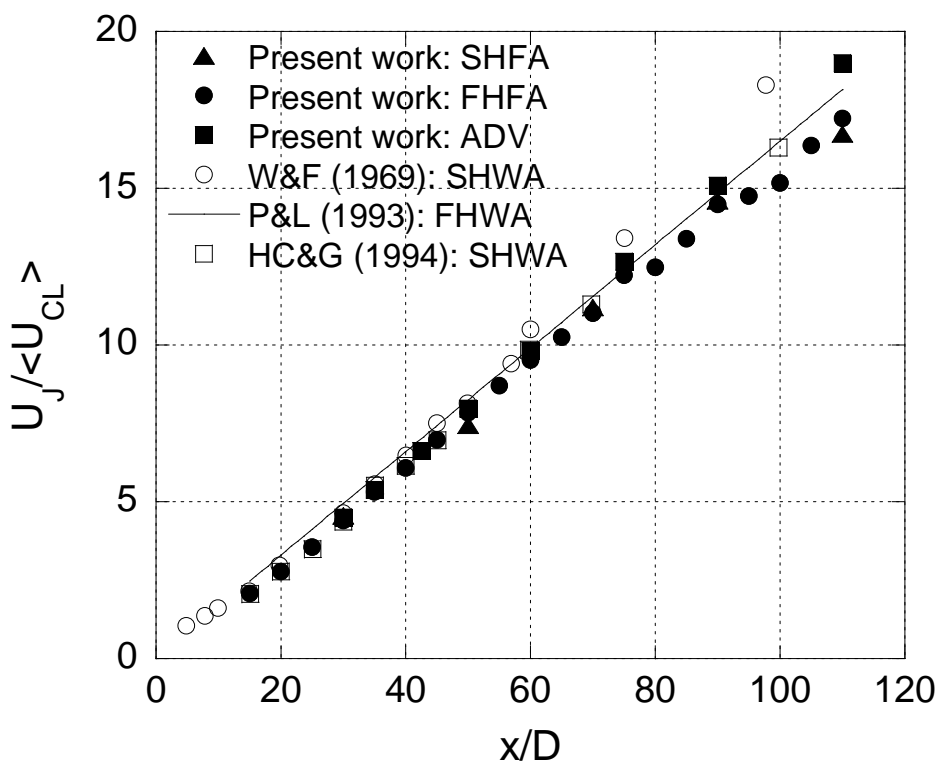

Figure 4. Downstream evolution of the inverse of the centerline axial mean velocity of an axisymmetric turbulent jet at $\mathrm{Re}=10,600: \boldsymbol{\Lambda}$, SHFA; •, FHFA; $\mathbf{}, \mathrm{ADV} ;$ ○, SHWA data of Wygnanski and Fiedler (1969); solid line, FHWA data of Panchapakesan and Lumley (1993); $\square$, SHWA data of Hussein, Capp and George (1994). 


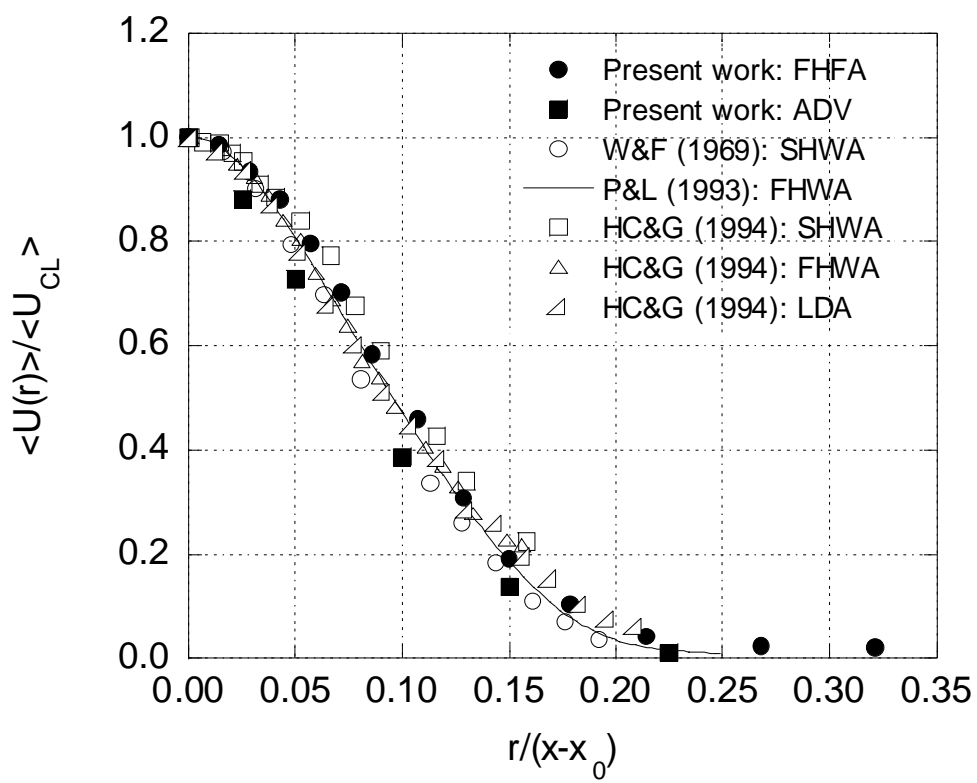

Figure 5. Mean axial velocity profile of an axisymmetric turbulent jet at $\operatorname{Re}=10,600$ $\left(x / D=35, x_{0}=0\right): \bullet$, FHFA; $\mathbf{\square}$, ADV; $\circ$, SHWA data of Wygnanski and Fiedler (1969); solid line, FHWA data of Panchapakesan and Lumley (1993); $\square$, SHWA data of Hussein, Capp and George (1994); $\Delta$, FHWA data of Hussein, Capp and George (1994); $\triangle$, LDA data of Hussein, Capp and George (1994). 


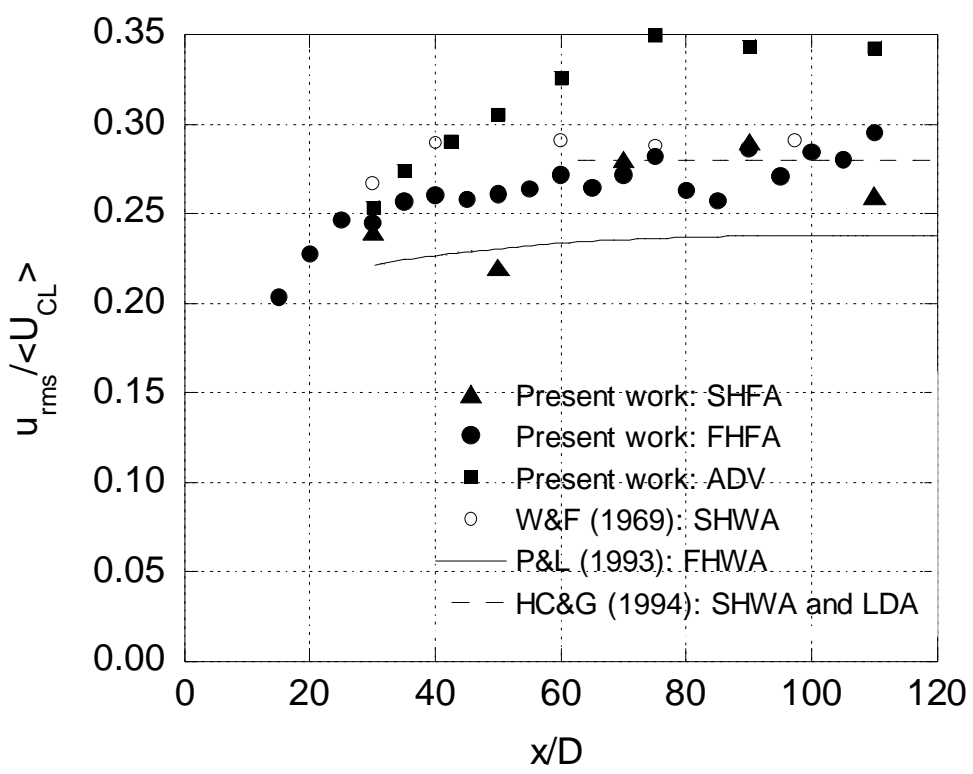

Figure 6. Downstream evolution of the normalized axial RMS velocity at the centerline of the jet at $\operatorname{Re}=10,600: \Delta, \operatorname{SHFA} ; \bullet$, FHFA; $\boldsymbol{\bullet}, \mathrm{ADV} ;$, SHWA data of Wygnanski and Fiedler (1969); solid line, FHWA data of Panchapakesan and Lumley (1993); broken line, SHWA and LDA data of Hussein, Capp and George (1994). 


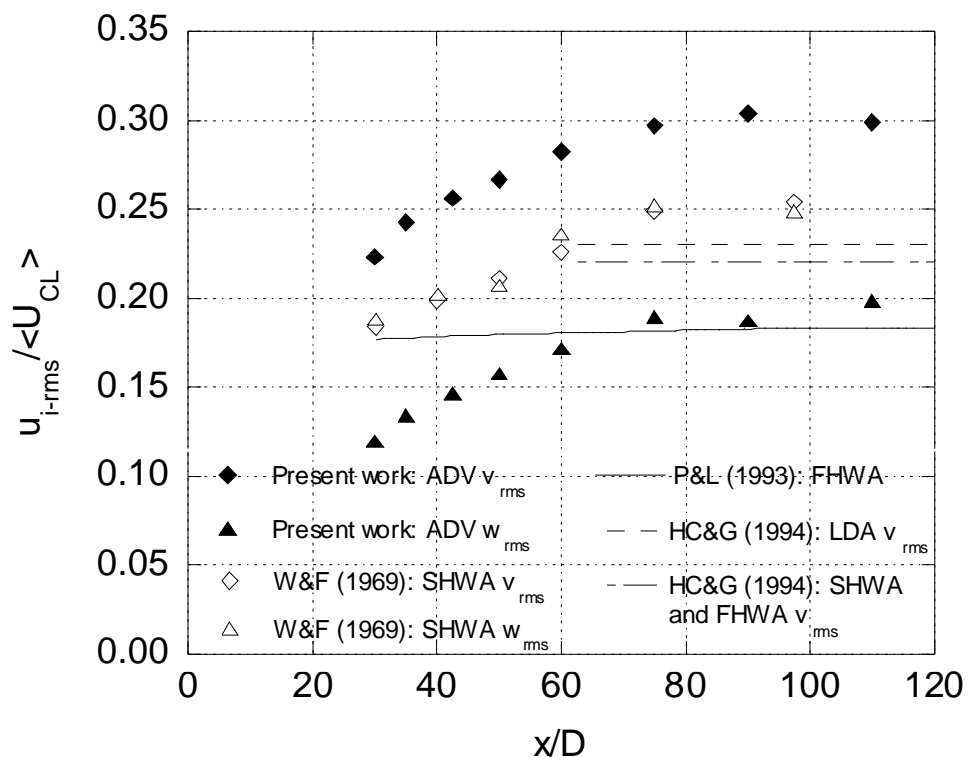

Figure 7. Downstream evolution of the normalized lateral RMS velocities at the centerline of the jet at $\operatorname{Re}=10,600: v_{r m s}: \star, w_{r m s}: \Delta, \mathrm{ADV} ; v_{r m s}: \diamond, w_{r m s}: \Delta$, SHWA data of Wygnanski and Fiedler (1969); solid line, FHWA data of Panchapakesan and Lumley (1993); - - LDA data of Hussein, Capp and George (1994); - - - SHWA and FHWA data of Hussein, Capp and George (1994). 

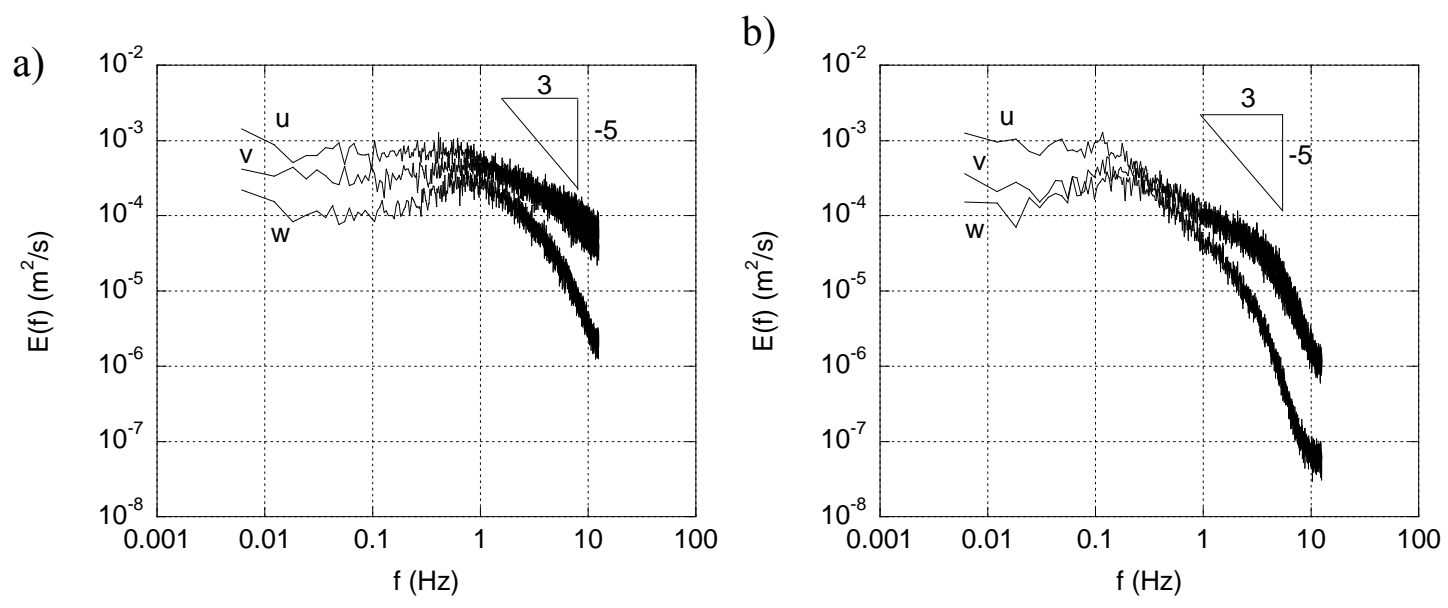

Figure 8 . Velocity spectra at the jet centerline and measured at a) $x / D=50$, and b) $x / D$ $=110$. 
a)

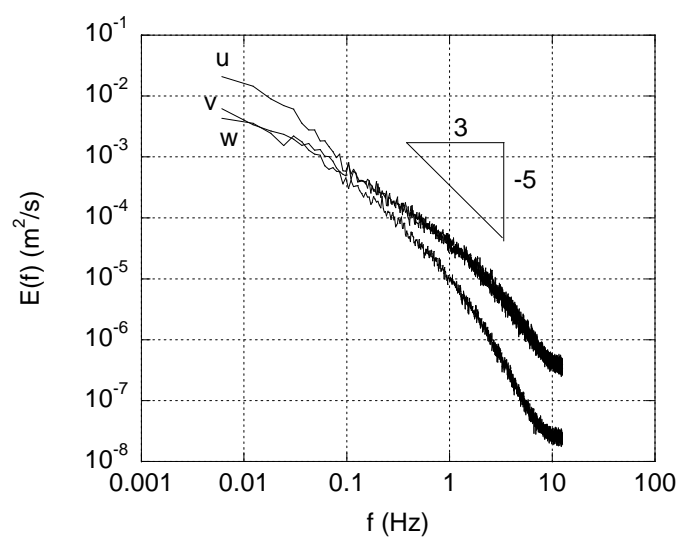

b)

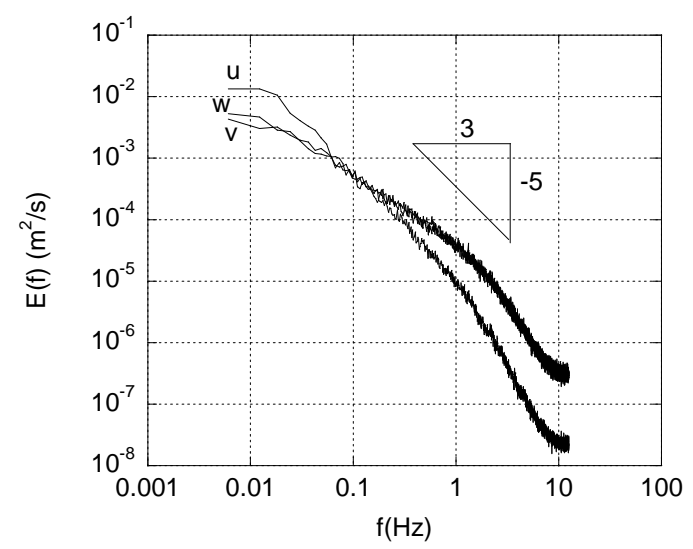

Figure 9. Velocity spectra in the flow generated by the RJA and measured at $x=110$ $\mathrm{cm}$ : a) orientation 1, and b) orientation 2 . 


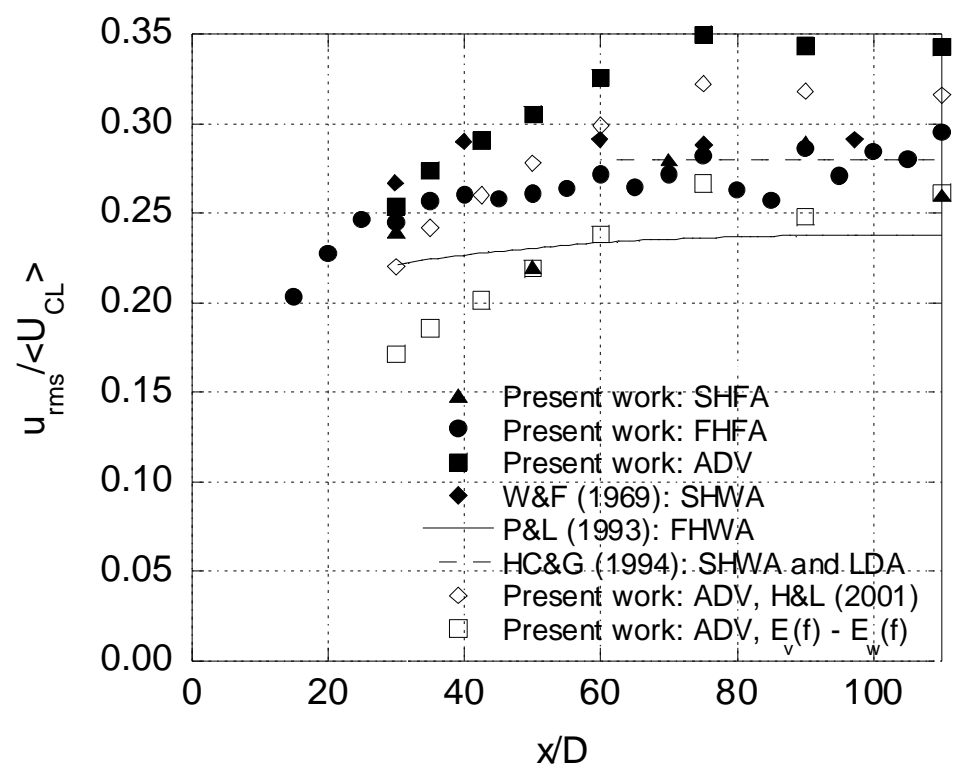

Figure 10. Normalized axial RMS velocities at the centerline of the jet measured by the ADV after the noise reduction method of Hurther and Lemmin (2001) was applied to the data: $\boldsymbol{\Delta}$, SHFA; •, FHFA; $\bullet$ ADV; O, SHWA data of Wygnanski and Fiedler (1969); solid line, FHWA data of Panchapakesan and Lumley (1993); broken line, SHWA and LDA data of Hussein, Capp and George (1994); $\diamond$, improved ADV data using the method of Hurther and Lemmin (2001); $\square$, improved ADV data subtracting the noise found from $E_{v}(f)-E_{w}(f)$. 


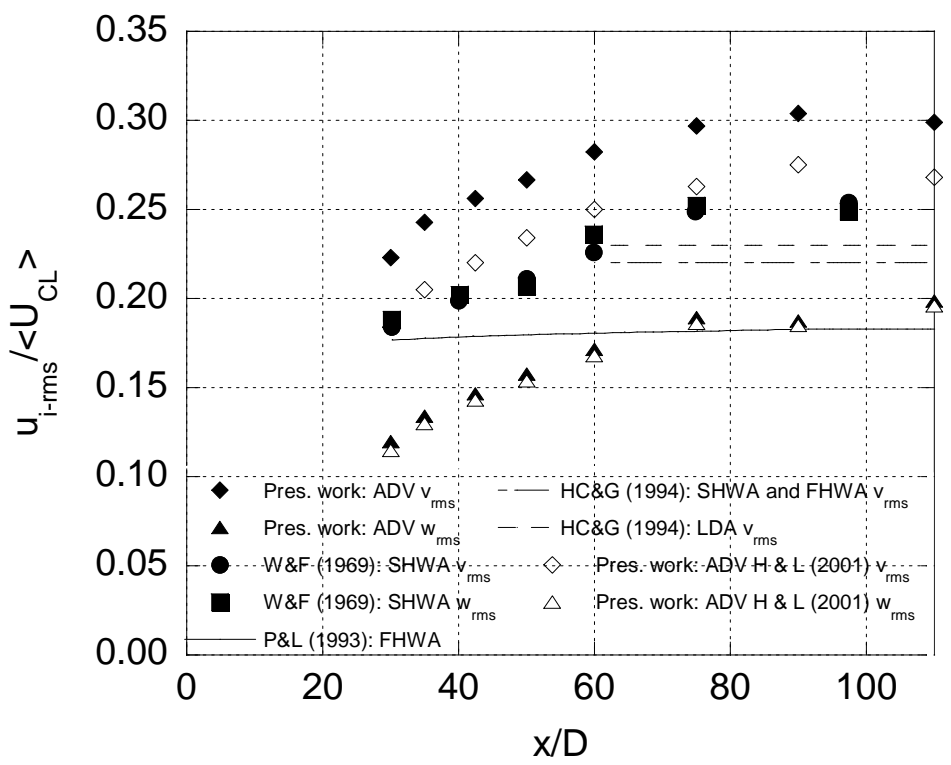

Figure 11. Normalized lateral RMS velocities at the centerline of the jet measured by the ADV after the noise reduction method of Hurther and Lemmin (2001) was applied to the data: $v_{r m s}: \bullet, w_{r m s}: \mathbf{\Lambda}, \mathrm{ADV} ; v_{r m s}: \bullet, w_{r m s}: \mathbf{m}$, SHWA data of Wygnanski and Fiedler (1969); solid line, FHWA data of Panchapakesan and Lumley (1993); - SHWA and FHWA data of Hussein, Capp and George (1994); - -, LDA data of Hussein, Capp and George (1994); $\mathrm{v}_{\mathrm{rms}}: \diamond$, improved ADV data using the method of Hurther and Lemmin (2001); $\mathrm{w}_{\mathrm{rms}}: \Delta$, improved ADV data using the method of Hurther and Lemmin (2001). 


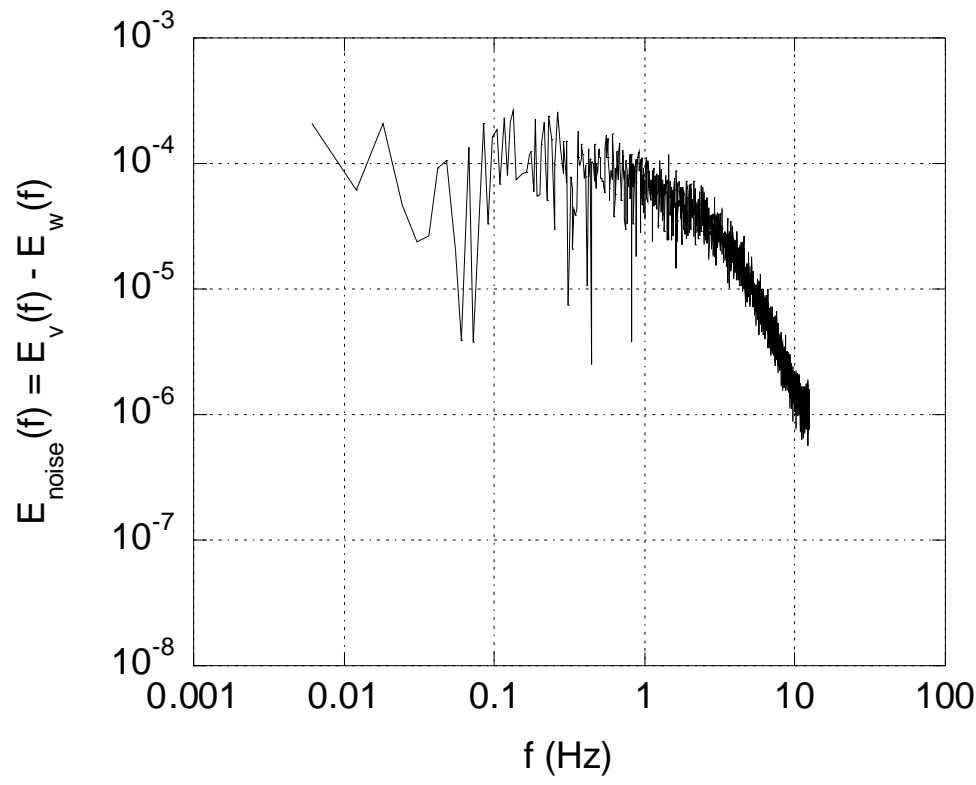

Figure 12 . Velocity noise spectrum of the jet at $\mathrm{x} / \mathrm{D}=110$ obtained from subtracting $E_{w}(f)$ from $E_{v}(f)$. 


\begin{tabular}{|c|c|c|c|c|c|c|c|c|c|c|c|c|c|c|}
\hline & \multicolumn{3}{|c|}{$\begin{array}{c}\text { Present work: } \\
\text { stationary hot-film } \\
\text { anemometry } \\
\text { (SHFA) }\end{array}$} & \multicolumn{3}{|c|}{$\begin{array}{l}\text { Present work: } \\
\text { flying hot-film } \\
\text { anemometry } \\
\text { (FHFA) }\end{array}$} & \multicolumn{3}{|c|}{$\begin{array}{c}\text { Present work: } \\
\text { ADV }\end{array}$} & $\begin{array}{c}\text { Wygnanski } \\
\text { and Fiedler } \\
(1969): \\
\text { stationary } \\
\text { hot-wire } \\
\text { anemometry } \\
\text { (SHWA) } \\
\text { x/D }<50\end{array}$ & $\begin{array}{c}\text { Wygnanski } \\
\text { and Fiedler } \\
(1969) \text { : } \\
\text { stationary } \\
\text { hot-wire } \\
\text { anemometry } \\
\text { (SHWA) } \\
\text { x/D > 50 }\end{array}$ & $\begin{array}{l}\text { Panchapakesan and } \\
\text { Lumley (1993): } \\
\text { flying hot-wire } \\
\text { anemometry } \\
\text { (FHWA) }\end{array}$ & $\begin{array}{c}\text { Hussein, Capp } \\
\text { and George } \\
\text { (1994): } \\
\text { stationary } \\
\text { hot-wire } \\
\text { anemometry } \\
\text { (SHWA) }\end{array}$ & $\begin{array}{l}\text { Hussein, Capp } \\
\text { and George } \\
\text { (1994): laser- } \\
\text { Doppler } \\
\text { anemometry } \\
\text { (LDA) }\end{array}$ \\
\hline $\mathrm{Re}$ & \multicolumn{3}{|c|}{10,600} & \multicolumn{3}{|c|}{10,600} & \multicolumn{3}{|c|}{10,600} & \multicolumn{2}{|c|}{$\frac{1}{100,000}$} & 11,000 & 95,500 & 95,500 \\
\hline$x_{0} / D$ & 0 & 4 & 4.18 & 0 & 4 & 2.89 & 0 & 4 & 5.5 & 3 & 7 & 0 & 4 & 4 \\
\hline$B$ & 6.29 & 5.92 & 5.90 & 6.34 & 5.94 & 6.05 & 5.99 & 5.66 & 5.43 & 5.7 & 5 & 6.06 & 5.9 & 5.8 \\
\hline$S$ & \multicolumn{3}{|c|}{-} & \multicolumn{3}{|c|}{0.101} & \multicolumn{3}{|c|}{0.099} & \multicolumn{2}{|c|}{0.084} & 0.096 & 0.102 & 0.094 \\
\hline
\end{tabular}

Table 1 . The velocity decay constant $(B)$, and spreading rate $(S)$ for an axisymmetric turbulent jet. Because the value of the decay constant is sensitive to the virtual origin, in the present work, $B$ was calculated using the virtual origins of i) Panchapakesan and Lumley $(1993)\left(x_{0} / D=0\right)$, ii) Hussein, Capp and George (1994) $\left(x_{0} / D=4\right)$, and iii) the value obtained using a simultaneous least-square fit of both $B$ and $x_{0}$ to the data. Note that radial profiles (and therefore the spreading rate) cannot be accurately measured using stationary hot-film anemometry because of the large turbulence intensities (and therefore flow reversals) at the edges of the jet. 


\begin{tabular}{|c|c|c|c|c|}
\hline \multirow{2}{*}{ ADV orientation } & \multicolumn{3}{|c|}{ ADV } & \multirow{2}{*}{ Flying hot-film } \\
\cline { 2 - 4 } & $u_{r m s}$ & $v_{r m s}$ & $w_{r m s}$ & $v_{r m s}$ \\
\hline \multirow{2}{*}{1} & ADV x & ADV y & ADV z & \multirow{2}{*}{$1.52 \pm 0.01$} \\
\cline { 2 - 4 } & $2.43 \pm 0.09$ & $1.81 \pm 0.07$ & $1.51 \pm 0.04$ & \\
\hline \multirow{2}{*}{2} & ADV z & ADV (negative) $\mathrm{x}$ & ADV (negative) y & \\
\cline { 2 - 4 } & $2.08 \pm 0.14$ & $1.76 \pm 0.01$ & $1.73 \pm 0.05$ & \\
\hline
\end{tabular}

Table 2. The RJA statistics measured by the ADV and flying hot-film. The units are $\mathrm{cm} / \mathrm{s}$. 


\begin{tabular}{|c|c|c|c|c|c|c|}
\hline $\mathrm{cm} / \mathrm{s}$ & \multicolumn{3}{|c|}{ Without background turbulence } & \multicolumn{3}{|c|}{ With background turbulence } \\
\hline ADV velocity & 0 & 10 & 20 & 0 & 10 & 20 \\
\hline \multirow{2}{*}{$<U>$} & $-0.03 \pm$ & $0.00 \pm$ & $0.01 \pm$ & $0.12 \pm$ & $-0.03 \pm$ & $-0.08 \pm$ \\
\hline & 0.42 & 0.01 & 0.01 & 0.02 & 0.45 & 0.19 \\
\hline \multirow{2}{*}{$<V>$} & $-0.17 \pm$ & $9.68 \pm$ & $19.25 \pm$ & $0.13 \pm$ & $9.78 \pm$ & $19.43 \pm$ \\
\hline & 0.26 & 0.03 & 0.35 & 0.06 & 0.06 & 0.21 \\
\hline \multirow{2}{*}{$<W>$} & $-0.41 \pm$ & $-0.16 \pm$ & $-0.17 \pm$ & $-0.24 \pm$ & $-0.27 \pm$ & $-0.38 \pm$ \\
\hline & 0.51 & 0.02 & 0.24 & 0.02 & 0.01 & 0.01 \\
\hline \multirow{2}{*}{$u_{r m s}$} & $0.47 \pm$ & $0.25 \pm$ & $0.33 \pm$ & $2.47 \pm$ & $2.32 \pm$ & $2.44 \pm$ \\
\hline & 0.08 & 0.01 & 0.01 & 0.01 & 0.03 & 0.04 \\
\hline \multirow{2}{*}{$v_{r m s}$} & $0.30 \pm$ & $0.22 \pm$ & $0.37 \pm$ & $1.81 \pm$ & $1.65 \pm$ & $1.69 \pm$ \\
\hline & 0.14 & 0.01 & 0.01 & 0.02 & 0.04 & 0.04 \\
\hline \multirow{2}{*}{$w_{r m s}$} & $0.19 \pm$ & $0.15 \pm$ & $0.27 \pm$ & $1.50 \pm$ & $1.45 \pm$ & $1.46 \pm$ \\
\hline & 0.06 & 0.01 & 0.01 & 0.02 & 0.01 & 0.06 \\
\hline
\end{tabular}

Table 3. Velocity statistics measured by the ADV. Column 1) a quiescent background with stationary ADV, column $2 \& 3$ ) a quiescent background with the ADV translating at a constant speed in the y-direction using a traversing mechanism, column 4) homogeneous isotropic turbulence with no mean flow, and column 5 \& 6 ) homogeneous isotropic turbulence with an artificially generated mean velocity by translating the $\mathrm{ADV}$ at a constant speed in the $\mathrm{y}$-direction using a traversing mechanism. 